\title{
Experiences of Saudi Female Students towards the Phenomena of Bullying Behaviors during Nursing Education Program
}

\author{
Lobna Khamis Mohamed ${ }^{1,2, *}$ \\ ${ }^{1}$ Nursing Administration Department, Faculty of Nursing, Tanta University, Egypt \\ ${ }^{2}$ Nursing Department, College of Applied Medical Sciences, University of Hafr Al-Batin, Saudi Arabia \\ *Corresponding author: lobnakhamis2020@gmail.com
}

Received March 11, 2019; Revised May 07, 2019; Accepted May 23, 2019

\begin{abstract}
Bullying is a growing problem in nursing education from the academia area to the clinical setting that is under-reported and tolerated by nursing students. Aim: The main aim is to explain the phenomena of bullying behaviors among Saudi female students during their study in nursing education program. Design: The study utilized a cross-sectional quantitative descriptive design. Setting: It conducted in the College of Applied Medical Sciences (CAMS) at University of Hafr Al-Batin (UHB) in Saudi Arabia. Participants: The sample consisted of (130) Saudi female nursing students. Tools: The instrument consists of four parts; the first part involves personal information. The second part contains 25 items of different types of bullying and the third part covers the consequences of bullying. The final part includes four closed ended questions about widespread learning environments (4 options), sources of bullying (7 options), coping strategies (9 options) and reasons for not reporting (8 options). Results: The current study confirmed that Saudi female nursing students experienced different forms of bullying behaviors in the traditional classroom and clinical settings. Recommendations: There is a need to establish policy for identifying the legal implications of bullying and integrating the bullying issue in the curriculum of nursing education program. Conclusion: There is an evidence for presence of bullying phenomena among Saudi female nursing students that deserve to be studied in nursing education and practice.
\end{abstract}

Keywords: bullying, experiences, consequences of bullying behaviors, coping strategies, nursing education

Cite This Article: Lobna Khamis Mohamed, "Experiences of Saudi Female Students towards the Phenomena of Bullying Behaviors during Nursing Education Program.” American Journal of Nursing Research, vol. 7, no. 4 (2019): 599-508. doi: 10.12691/ajnr-7-4-12.

\section{Introduction}

In contemporary society, bullying becomes a serious problem that negatively affects the students, educators, workplace, quality of training, and patient care [1,2]. Bullying defined as a form of interpersonal violence or personal harassment that directed against someone who cannot easily defend him or herself [3]. It is an aggressive, intentional behavior that is carried out by a group or an individual, repeatedly and over time [4]. During the bullying, the individuals' personality subject to long periods of humiliation, scolding, ignoring, isolation, loss of dignity and other traumatizing behaviors. Bullying is a situation that affects the development and the future life of the individual [5].

Bullying in nursing is a widespread problem from academia area to the clinical settings [6]. It occurs in nursing practice, as well as in nursing education at all levels and in all contexts. It often involves power abuse, feelings of defenselessness, injustice, and undermining dignity. Bullying is an apparent contradiction in a nursing profession where the importance of caring is considered to be absolute [3]. It may be directed upward (faculty against students), downward (students against faculty), or horizontally (student to student or faculty to faculty) [7]. Bullying is an umbrella term that involves aggressiveness, mobbing, incivility, horizontal and workplace violence, harassment and verbal abuse [8] and [9].

\subsection{Literature Review}

In nursing, bullying is not a new concept; it is often experienced in healthcare settings, practice areas, and University environments [10]. The undergraduate students are commonly subject to bullying behaviors in the classroom and clinical setting during their education that negatively cause verbal, physical, relational, and social exclusion [11]. Bullying behaviors can spread through the nursing workforce and infect the future generations of nurses [12]. Additionally, students have lower levels of social support and higher psychological demand due to being in the learning role and having only temporary bonds with specific nursing units' work and staff [3]. 
Nursing students can be experienced bullying during interactions with colleagues, instructors, patients, family members, or health care staff. The experiences of bullying in the academic nursing settings accompanied by anxiety, poor performance, leaving nursing programs, that leads to toxic working environment that adversely affect patient outcomes [6]. Cyberbullying is a new form of bullying in the academic setting that emerged due to use of modern communication technologies. It carried out via abusive text messages that sent through e-mail, and social networking sites (e.g. Facebook and Twitter). It conveyed an offensive language, images or vulgar comments that bully of others [13].

Based on literature, bullying against university students are well-recognized phenomena. An Australian study conducted by Hopkins, et al. [14] and a Canadian study established by Clarke, et al. [15] concluded that the nursing students are exposed to a significant risk from various forms of bullying in the clinical setting. In a United Kingdom (UK) study, Ferns and Meerabeau, [16] reported that $45.1 \%$ of nursing students experienced verbal bullying. In Egypt, Kassem, et al. [17] reported that the most of nursing students $(\mathrm{N}=338)$ were experiencing moderate level of bullying behaviors. In a New Zealand study, Foster, et al. [18] suggested that $90 \%$ of nursing students had experienced some forms of bullying behaviors.

The consequences of experiencing bullying can negatively create an unsafe environment, as well as behavioral and emotional difficulties that interfere with learning [2]. The most common symptoms of bullying include headache, bad temper, stomachache, backache, nervousness, inferiority, difficulties in sleeping, dizziness, loneliness, tired in the morning, and helplessness [19]. The effect of bully not only limited to poor psychosocial adjustment, lack academic achievement, weak relationships formation, but also reduce concentration, success, motivation, and self-confidence [5].

The existence of bullying harms the physical and mental health of nursing students that complicated by feelings of fear and embarrassment. When bullying occurs among nursing students, it negatively affect students' education lives and preferences after graduation [20]. Wilkins, [9] identified the root cause of bullying behaviors often starts early in the university in the student nurse's career, which leads to the continuation of bullying in nursing practice resulting in nurses accepting these behaviors as the norm and part of the workplace.

Coping strategies is the behavioral and psychological efforts that the individual employ to reduce or tolerate the stressful situations. It is important for the student nurse to select the best coping method as wrong strategy may worsen the situation [21]. The literature identifies many coping strategies that the student nurses can be used to adapt with bullying behaviors including religion, acceptance, cognitive reappraisal, humor and self-blame $[9,22]$.

\subsection{Significance of the Problem}

Globally, the prevalence rates document the number of students who involved in bullying as victims ranged from $7 \%$ to $43 \%$, and as perpetrators ranged from $5 \%$ to $44 \%$ [23]. Recently, the problem have become more prevalent.
However, there is no research addressed the bullying phenomena among nurse students in Saudi Arabia although. Identification of bullying experienced by nursing students in the education environment is an essential issue for coping with these behaviors. Therefore, this study emphasizes the experiences of bullying behaviors and coping strategies among Saudi female students during their nursing education.

\subsection{Aim}

The main aim for this research is to explain the phenomena of bullying among nursing students during their study in nursing education program.

The more specific objectives aimed to state the types and frequency of bullying behaviors experienced by nursing student during their study in nursing program, determine the most likely sources to be the bully and consequences of these bullying behaviors, identify the coping strategies to deal with these behaviors and recognize the reasons for not reporting about bullying behaviors.

\subsection{Research Questions}

The present study aimed to answer the following research questions:

1. What are the most widespread learning environments that involve bullying behaviors?

2. What are the types and frequency of bullying behaviors' types that nursing students experienced during nursing education?

3. Who is most likely source to "be the bully" during their study in nursing program?

4. What are the consequences or the effect of bullying behaviors on nursing students?

5. What are the coping strategies used by nursing student to deal with bullying behaviors?

6. What are the reasons for not reporting about bullying behaviors?

7. Is there a relationship between experienced bullying behaviors' types and consequences with nursing students' academic year?

\section{Methodology}

\subsection{Design}

The present study was utilized a cross-sectional quantitative descriptive design to answer the research's questions.

\subsection{Setting}

This study was conducted in the nursing department of Applied Medical Sciences College at University of Hafr Al-Batin (UHB) in Kingdom Saudi Arabia.

\subsection{Participants}

Convenience sample was used which consisted of (130) Saudi female nursing students who were accepted to 
participate in the research anonymously. The students enrolled at sophomores, juniors, senior and internship during the academic year 2018/2019. The inclusion criteria of participants' selection stated that all female nursing students must have an experience in clinical learning environment; therefore, the first academic year was excluded from the sample because the clinical training starts from the second grade, Additionally, another exclusion criterion was the students' refusing to participate in the study.

\subsection{Tools}

The questionnaire was developed by the researcher based on extensive literature review. The questionnaire was translated into Arabic by the researcher to be understandable for all students' levels during stage of data collection. Data were collected through self-administered questionnaire. The questionnaire took approximately from 10 to 15 minutes for each student. The estimated time for data collection started on January $5^{\text {th }}, 2019$ to the mid of March 2019. The instrument consists of four parts.

The first part involves personal information as age, and academic year, the presence bullying behaviors or no, the extent of bullying behaviors and the effect of bullying behaviors on students' performance.

The second part contains items of verbal bullying behaviors (9 items), physical bullying behaviors (6 items) and psychological bullying behaviors (10 items) to assess the most frequent type of bullying behaviors that experienced by nursing student during their study in nursing program.

The third part covers the physiological symptoms (7 items) of bullying behaviors, psychological symptoms (8 items), and behavioral symptoms (4 items) to estimate the frequency of bullying behaviors' consequences. Responses for answering the second and third parts of questionnaire were measured on a 5-point Likert rating scale ranging from (0) never to always (4).

The fourth part includes four closed ended questions asking about the following issues:

1. The widespread learning environments that involve bullying behaviors (4 options).

2. The most likely source to be the bully during the study in nursing program (7 options).

3. The frequency of coping strategies that used by nursing student to deal with bullying behaviors (9 options)

4. The frequency of reasons for not reporting about bullying behaviors (8 options).

\subsection{Ethical Consideration}

The approval for conducting the study was obtained from the authoritative personnel (Deanship of Studies \& Scientific Research) at the UHB prior to initiate the data collection. The purpose of the research was explained to nursing students and oral consent was obtained. The participants' involvement in the study was voluntary without penalty that might arise from withdrawal or nonparticipation. They were informed that their answers would be kept confidentially.

\subsection{Validity and Reliability}

The panel of seven experts from nursing management specialty was invited for revising the questionnaire, as well as measuring face and content validity. Necessary modifications were done accordingly. The Cronbach's coefficient alpha test value was equal 0.87 and the testretest reliability value for nominal data was greater than 0.95. Based on questionnaire revision, a pilot study was carried out on $10 \%$ of participants (13 nurse students) from nursing department at the previous mentioned setting (excluded from the study sample) who were selected randomly for measuring test-retest reliability.

\subsection{Statistical Analysis}

SPSS (version 20) was used for data analysis. The Mean, Standard Deviation (SD) and the Range (minimum - maximum) were used to describe the quantitative variables, while proportions and percentages were used to describe the qualitative variables. Fisher's exact test is a statistical significance test, which used for analysis of contingency tables. The significance level was stated at $\square=0.05$.

\section{Results}

Table 1. Sociodemographic characteristics of female nursing students

\begin{tabular}{|l|c|c|}
\hline Demographic characteristics & No. & $\%$ \\
\hline Age & 36 & 27.7 \\
\hline 20 Years or less & 75 & 57.7 \\
\hline 21 to 23 Years & 19 & 14.6 \\
\hline 24 Years or more & $21.58 \pm 2.22$ \\
\hline Mean \pm SD & \multicolumn{3}{|l|}{} \\
\hline Academic year & 19 & 14.6 \\
\hline Sophomore & 30 & 23.1 \\
\hline Junior & 60 & 46.2 \\
\hline Senior & 21 & 16.2 \\
\hline Interns &
\end{tabular}

Did you experience bullying behaviors during the period of studying?

\begin{tabular}{|l|c|c|}
\hline Yes & 109 & 83.8 \\
\hline No & 21 & 16.2 \\
\hline
\end{tabular}

What is the extent of bullying behaviors a problem in the academic environment?

\begin{tabular}{|l|c|c|}
\hline No problem & 1 & 0.8 \\
\hline Moderate problem & 25 & 19.2 \\
\hline Major problem & 104 & 80 \\
\hline Are bullying behaviors affect the students' performance? & 77 & 59.2 \\
\hline Yes & 53 & 40.8 \\
\hline No & 53
\end{tabular}

The overall response rate was $84 \%$ out of 153 female nursing students in academic year of 1440/2019, who agree to participate in data collection. Table 1 shows sociodemographic data of Saudi female nursing students. It was apparent that $57.7 \%$ of the studied sample were in age group 21-23 years old with mean score 21.58 \pm 2.22 , and $46.2 \%$ were enrolled in senior year. The majority of respondents (83.8\%) experienced bullying behaviors during the period of studying in nursing education program. Furthermore, $80 \%$ of participants estimated the 
extent of bullying behaviors as a major problem in the academic environment, and $59.2 \%$ of them reported that bullying behaviors would affect their performance.

Table 2 reveals the frequency of bullying behaviors as experienced by female nursing students. Concerning verbal bullying behaviors, $45.4 \%$ \& 36.9\% always experience threatening with poor evaluation and using belittle behavior for efforts respectively. The highest percents of respondents $(40 \%, 31.5 \%$ \& $27.7 \%)$ often experience failing to acknowledge significant clinical or academic achievement, using offensive language or inappropriate non-verbal signs in front of others, and persistent criticism of work/effort respectively. Around more than one third of participants (39.2\% \& 28.5\%) sometimes experience yelling or shouting angry and intimidating with disciplinary measures respectively, while $41.5 \%$ and $39.2 \%$ of participants never experience spreading of malicious rumors and inappropriate jokes against them respectively.

Regarding physical bullying behaviors, 30\% of the studied sample always experience excessive monitoring of work. Around two thirds (34.6\% \& 33.8\%) of female nursing students often experience continuously assigning tasks over their capacity and being physically isolated. More than half of participants (58.5\%) rarely experience changing duties without being told, while 58.5\% \& $53.8 \%$ of them never experience actual threating physically and removing areas of responsibility without warning respectively.

Pertaining psychological behaviors, 31.5\% \& 26.9\% of participants always experience repeating reminders of mistakes and limiting self-expression respectively.
Around one third of respondents (33.8\%, 31.5\% \& 24.6\%) often experience attempting to demoralize them, using undue pressure to produce order and insisting to give them negative criticism respectively. Moreover, $40.8 \%$ and $27.7 \%$ of female nursing students reported that they never treated with hostility and denial the learning opportunities respectively.

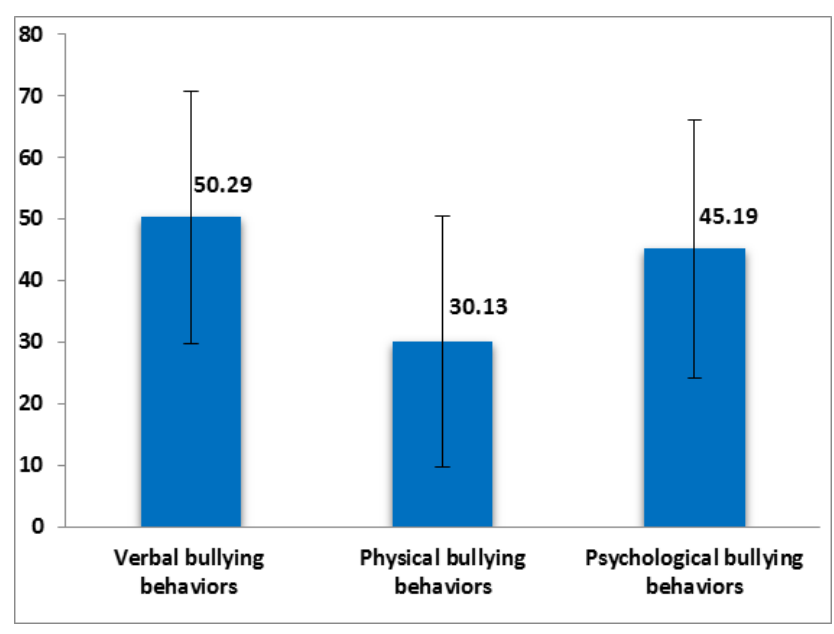

Figure 1. Total mean values of bullying behaviors' types experienced by Saudi female nursing students

Figure 1 represents the total mean values of bullying behaviors' types experienced by female nursing students. The most frequently reported bullying behaviors' types by participants were verbal abuse (mean= 50.29), followed by psychological abuse (mean $=45.19$ ) and lastly physical abuse (mean= 30.13).

Table 2. Frequency of bullying behaviors' items as experienced by female nursing students

\begin{tabular}{|c|c|c|c|c|c|c|c|c|c|c|c|}
\hline \multirow{2}{*}{\multicolumn{2}{|c|}{ Types of bullying behaviors }} & \multicolumn{2}{|c|}{ Never } & \multicolumn{2}{|c|}{ Rarely } & \multicolumn{2}{|c|}{ Sometimes } & \multicolumn{2}{|c|}{ often } & \multicolumn{2}{|c|}{ Always } \\
\hline & & $\mathbf{N}$ & $\%$ & $\mathbf{N}$ & $\%$ & $\mathbf{N}$ & $\%$ & $\mathbf{N}$ & $\%$ & $\mathbf{N}$ & $\%$ \\
\hline \multirow{9}{*}{ 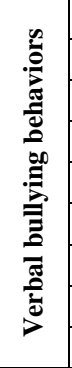 } & 1. Yelling or shouting angry. & 7 & 5.4 & 16 & 12.3 & 51 & 39.2 & 32 & 24.6 & 24 & 18.5 \\
\hline & 2. Using offensive language or inappropriate non-verbal signs in front of others. & 19 & 14.6 & 14 & 10.8 & 38 & 29.2 & 41 & 31.5 & 18 & 13.8 \\
\hline & 3. Using belittle or undermine behavior for your work or efforts. & 12 & 9.2 & 26 & 20.0 & 14 & 10.8 & 30 & 23.1 & 48 & 36.9 \\
\hline & 4. Spreading of malicious rumors or allegations against you. & 54 & 41.5 & 39 & 30.0 & 15 & 11.5 & 8 & 6.2 & 14 & 10.8 \\
\hline & 5. Threatening you with poor evaluation. & 14 & 10.8 & 12 & 9.2 & 28 & 21.5 & 17 & 13.1 & 59 & 45.4 \\
\hline & 6. Failing to acknowledge significant clinical or academic achievement. & 20 & 15.4 & 24 & 18.5 & 20 & 15.4 & 52 & 40.0 & 14 & 10.8 \\
\hline & 7. Intimidating with disciplinary measures. & 12 & 9.2 & 27 & 20.8 & 37 & 28.5 & 32 & 24.6 & 22 & 16.9 \\
\hline & 8. Persistent criticism of your work and effort. & 25 & 19.2 & 33 & 25.4 & 22 & 16.9 & 36 & 27.7 & 14 & 10.8 \\
\hline & 9. Inappropriate jokes were made about you. & 51 & 39.2 & 32 & 24.6 & 22 & 16.9 & 10 & 7.7 & 15 & 11.5 \\
\hline \multirow{6}{*}{ 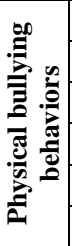 } & 10. Continuously assigning tasks over your capacity. & 21 & 16.2 & 28 & 21.5 & 21 & 16.2 & 45 & 34.6 & 15 & 11.5 \\
\hline & 11. Being ignored or physically isolated. & 9 & 6.9 & 26 & 20.0 & 29 & 22.3 & 44 & 33.8 & 22 & 16.9 \\
\hline & 12. Excessive monitoring of your work. & 25 & 19.2 & 32 & 24.6 & 13 & 10.0 & 21 & 16.2 & 39 & 30.0 \\
\hline & 13. Changing your duties without you being told. & 25 & 19.2 & 76 & 58.5 & 18 & 13.8 & 3 & 2.3 & 8 & 6.2 \\
\hline & 14. Areas of responsibility were removed from you without warning. & 70 & 53.8 & 31 & 23.8 & 20 & 15.4 & 0 & 0.0 & 9 & 6.9 \\
\hline & 15. Actual threats physically abused. & 76 & 58.5 & 22 & 16.9 & 18 & 13.8 & 11 & 8.5 & 3 & 2.3 \\
\hline \multirow{10}{*}{ 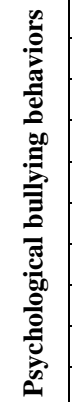 } & 16. Disparaging negative remarks about you. & 13 & 10.0 & 17 & 13.1 & 50 & 38.5 & 35 & 26.9 & 15 & 11.5 \\
\hline & 17. Limiting self-expression. & 21 & 16.2 & 28 & 21.5 & 27 & 20.8 & 19 & 14.6 & 35 & 26.9 \\
\hline & 18. Using humiliating behavior in front of others. & 33 & 25.4 & 36 & 27.7 & 38 & 29.2 & 12 & 9.2 & 11 & 8.5 \\
\hline & 19. Persistent ignorance for your opinions and views. & 17 & 13.1 & 22 & 16.9 & 43 & 33.1 & 30 & 23.1 & 18 & 13.8 \\
\hline & 20. Undue pressure to produce order. & 14 & 10.8 & 14 & 10.8 & 34 & 26.2 & 41 & 31.5 & 27 & 20.8 \\
\hline & 21. Attempting to demoralize you. & 13 & 10.0 & 27 & 20.8 & 28 & 21.5 & 44 & 33.8 & 18 & 13.8 \\
\hline & 22. Repeating reminders of your errors or mistakes & 17 & 13.1 & 13 & 10.0 & 35 & 26.9 & 18 & 13.8 & 41 & 31.5 \\
\hline & 23. Treated with hostility. & 53 & 40.8 & 33 & 25.4 & 24 & 18.5 & 10 & 7.7 & 10 & 7.7 \\
\hline & 24. Insist to give me negative criticism. & 30 & 23.1 & 17 & 13.1 & 28 & 21.5 & 32 & 24.6 & 23 & 17.7 \\
\hline & 25. Denial the learning opportunities. & 36 & 27.7 & 35 & 26.9 & 35 & 26.9 & 10 & 7.7 & 14 & 10.8 \\
\hline
\end{tabular}


Table 3. Frequency of bullying behaviors' consequences as experienced by female nursing

\begin{tabular}{|c|c|c|c|c|c|c|c|c|c|c|c|}
\hline \multirow{2}{*}{\multicolumn{2}{|c|}{ Consequences of bullying behaviors }} & \multicolumn{2}{|c|}{ Never } & \multicolumn{2}{|c|}{ Rarely } & \multicolumn{2}{|c|}{ Sometimes } & \multicolumn{2}{|c|}{ often } & \multicolumn{2}{|c|}{ Always } \\
\hline & & $\mathbf{N}$ & $\%$ & $\mathbf{N}$ & $\%$ & $\mathbf{N}$ & $\%$ & $\mathbf{N}$ & $\%$ & $\mathbf{N}$ & $\%$ \\
\hline \multirow{7}{*}{ 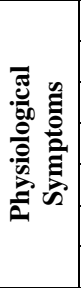 } & 1. Feeling of extreme fatigue or exhaustion. & 7 & $5.4 \%$ & 12 & $9.2 \%$ & 40 & $30.8 \%$ & 28 & $21.5 \%$ & 43 & $33.1 \%$ \\
\hline & 2. Being sweat or shaking & 43 & $33.1 \%$ & 26 & $20.0 \%$ & 26 & $20.0 \%$ & 13 & $10.0 \%$ & 22 & $16.9 \%$ \\
\hline & 3. Losing weight & 28 & $21.5 \%$ & 22 & $16.9 \%$ & 42 & $32.3 \%$ & 16 & $12.3 \%$ & 22 & $16.9 \%$ \\
\hline & 4. Gaining weight & 71 & $54.6 \%$ & 21 & $16.2 \%$ & 14 & $10.8 \%$ & 8 & $6.2 \%$ & 16 & $12.3 \%$ \\
\hline & 5. Raising blood pressure & 46 & $35.4 \%$ & 20 & $15.4 \%$ & 29 & $22.3 \%$ & 17 & $13.1 \%$ & 18 & $13.8 \%$ \\
\hline & 6. Having Insomnia & 13 & $10.0 \%$ & 15 & $11.5 \%$ & 32 & $24.6 \%$ & 25 & $19.2 \%$ & 45 & $34.6 \%$ \\
\hline & 7. Losing of appetite & 28 & $21.5 \%$ & 23 & $17.7 \%$ & 34 & $26.2 \%$ & 10 & $7.7 \%$ & 35 & $26.9 \%$ \\
\hline \multirow{8}{*}{ 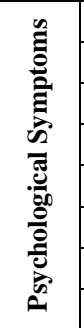 } & 8. Thinking about leaving profession & 31 & $23.8 \%$ & 24 & $18.5 \%$ & 30 & $23.1 \%$ & 11 & $8.5 \%$ & 34 & $26.2 \%$ \\
\hline & 9. Getting angry/anxious & 13 & $10.0 \%$ & 13 & $10.0 \%$ & 33 & $25.4 \%$ & 29 & $22.3 \%$ & 42 & $32.3 \%$ \\
\hline & 10. Getting panic attacks & 21 & $16.2 \%$ & 33 & $25.4 \%$ & 29 & $22.3 \%$ & 20 & $15.4 \%$ & 27 & $20.8 \%$ \\
\hline & 11. Feeling depression or sad & 18 & $13.8 \%$ & 27 & $20.8 \%$ & 20 & $15.4 \%$ & 33 & $25.4 \%$ & 32 & $24.6 \%$ \\
\hline & 12. Being low self-esteem & 44 & $33.8 \%$ & 21 & $16.2 \%$ & 23 & $17.7 \%$ & 14 & $10.8 \%$ & 28 & $21.5 \%$ \\
\hline & 13. Becoming dissatisfied & 19 & $14.6 \%$ & 16 & $12.3 \%$ & 24 & $18.5 \%$ & 32 & $24.6 \%$ & 39 & $30.0 \%$ \\
\hline & 14. Increasing absenteeism & 23 & $17.7 \%$ & 27 & $20.8 \%$ & 35 & $26.9 \%$ & 17 & $13.1 \%$ & 28 & $21.5 \%$ \\
\hline & 15. Being fearfulness & 30 & $23.1 \%$ & 22 & $16.9 \%$ & 26 & $20.0 \%$ & 21 & $16.2 \%$ & 31 & $23.8 \%$ \\
\hline \multirow{4}{*}{ 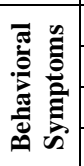 } & 16. Becoming fast irritable & 19 & $14.6 \%$ & 26 & $20.0 \%$ & 25 & $19.2 \%$ & 29 & $22.3 \%$ & 31 & $23.8 \%$ \\
\hline & 17. Becoming withdraw & 24 & $18.5 \%$ & 22 & $16.9 \%$ & 44 & $33.8 \%$ & 16 & $12.3 \%$ & 24 & $18.5 \%$ \\
\hline & 18. Becoming aggressive & 65 & $50.0 \%$ & 22 & $16.9 \%$ & 15 & $11.5 \%$ & 10 & $7.7 \%$ & 18 & $13.8 \%$ \\
\hline & 19. Increasing consumption of tobacco & 109 & $83.8 \%$ & 12 & $9.2 \%$ & 4 & $3.1 \%$ & 2 & $1.5 \%$ & 3 & $2.3 \%$ \\
\hline
\end{tabular}

Table 3 describes the frequency of bullying behaviors' consequences as experienced by female nursing students. Pertaining physiological symptoms, around one third (34.6\%, 33.1\% \& 26.9\%) of female nursing students always feel of physiological symptoms by having insomnia, feeling of extreme fatigue and losing of appetite respectively, while $32.3 \%$ of them sometimes feel the effect of bullying by losing weight. The highest percents of respondents $(54.6 \%, 35.4 \%$ \& 33.1\%) never feel gaining weight, raising blood pressure and being sweat or shaking.

As regards psychological symptoms, 32.3\%, 30\%, 26.2\% \& $23.8 \%$ of participants always feel getting angry/anxious, becoming dissatisfied, thinking about leaving profession and being fearfulness respectively. Furthermore, 25.4\% of respondents often feel depression or sad, while $26.9 \%$ of them sometimes feel increasing absenteeism. Around one third (33.8\%) of female nursing students never feel of being low self-esteem, while $25.4 \%$ of them rarely feel getting panic attacks.

Concerning behavioral symptoms, $23.8 \%$ of respondents always feel of becoming fast irritable, while $33.8 \%$ of them often feel of becoming withdrawal. The majority (83.8\% \& 50\%) of participants never feel of increasing consumption of tobacco or becoming aggressive respectively.

Figure 2 represents the total mean values of bullying behaviors' consequences experienced by female nursing students. The most frequently reported bullying behaviors' consequences by participants were psychological symptoms $($ mean $=52.84)$, followed by physiological symptoms $($ mean $=46.70)$ and finally behavioral symptoms (mean= 33.32).

Figure 3 shows the frequency of most widespread learning environments of bullying behaviors. The female nursing students reported that clinical practice setting (39.2\%) is the most widespread learning environments that involve bullying behaviors, followed by traditional classroom (38.5\%), then skills laboratory (20\%) and finally interactive screen (2.3\%).

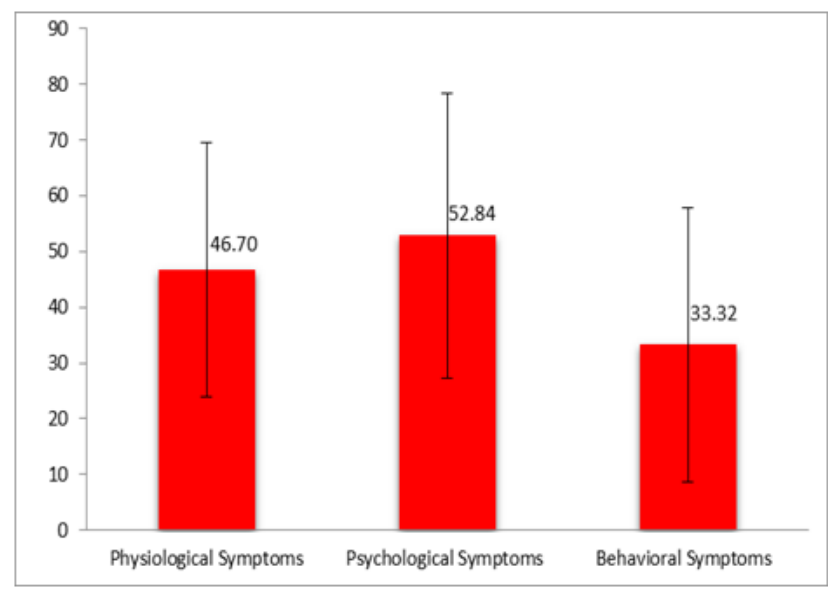

Figure 2. Total mean values of bullying behaviors' consequences experienced by Saudi female nursing students

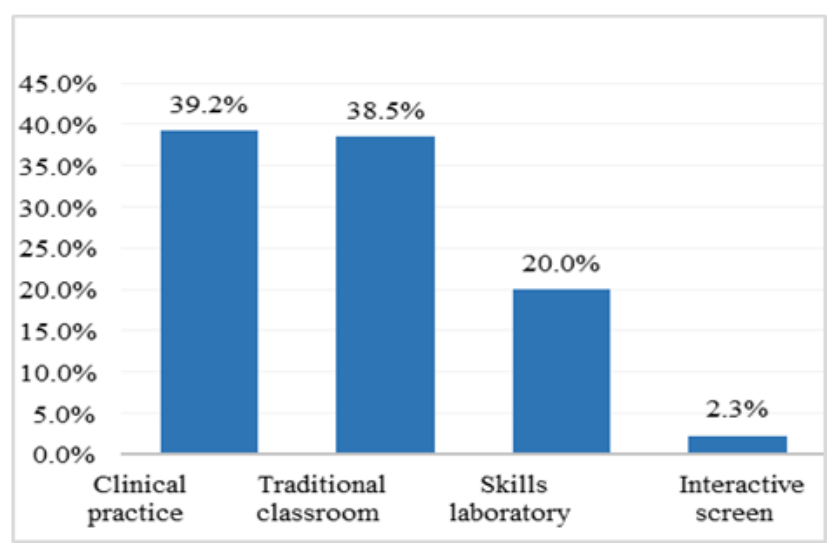

Figure 3. Frequency of most widespread learning environments of bullying behaviors

Figure 4 illustrates the most likely sources to be bully among female nursing students. It was observed that $58.5 \%$ of respondents reported that classmate was the most likely source to be the bully, followed by faculty 
members with 53.1\%, then clinical instructors with 50\% and after that patients or patients' family with $47.7 \%$. The least three frequent perpetrators of bullying behaviors were nursing staff (38.5\%), administrative staff (33.8\%), and finally physician (17.7\%).

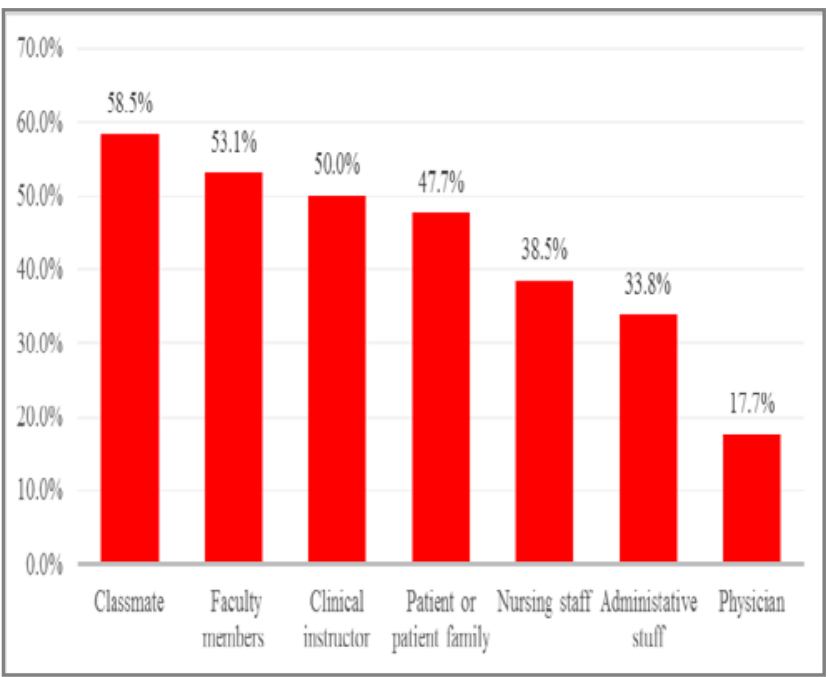

Figure 4. Most likely sources to be bully among Saudi female nursing students

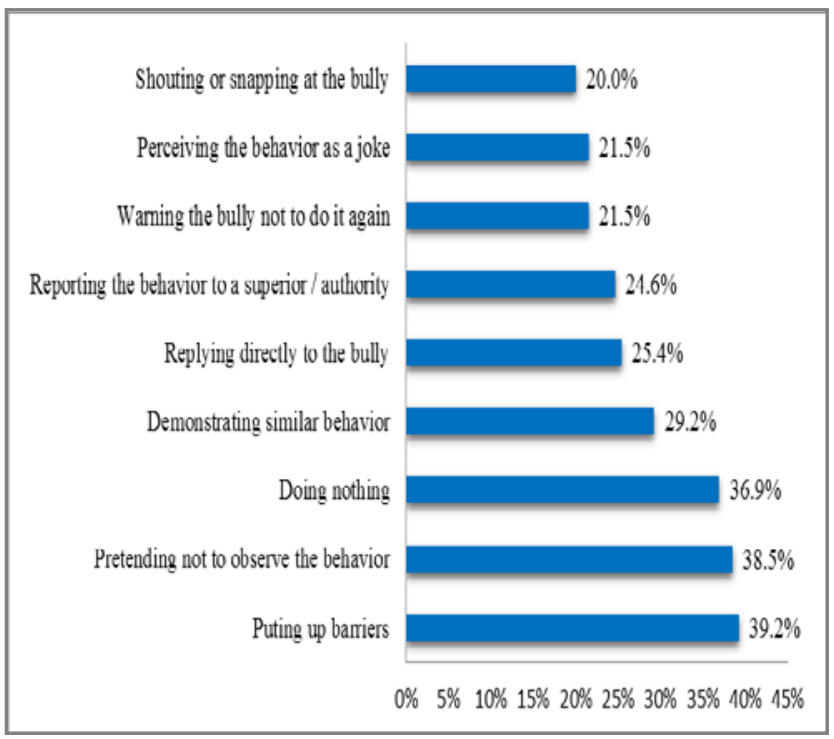

Figure 5. Frequency of coping strategies to adopt with bullying behaviors among Saudi female nursing students

Figure 5 displays the frequency of coping strategies to adopt with bullying behaviors among female nursing students. The most frequently coping strategies of bullying behaviors experienced by participants were putting up barriers (39.2\%) followed by pretending not to observe the behavior (38.5\%) then doing nothing (36.9\%), after that demonstrated similar behavior (29.2\%) and replying directly to the bully (25.4\%). The least frequently reported coping strategies were shouting at the bully (20\%), followed by perceiving the behavior as a joke (21.5\%) and warning the bully not to do it again, and finally reporting to a superior/authority.

Figure 6 states the frequency for reasons of not reporting about bullying behaviors among female nursing students. The most frequently reasons of not reporting bullying behaviors experienced by participants were fearing of punishment (46.2\%), followed by fearing of poor evaluation (43.8\%), then doing nothing (41.5\%), after that labeling a trouble maker (39.2\%), and finally do not know whom to report (27.7\%). The least frequently reasons of not reported bullying behaviors were not worth effort (13.8\%), followed by able to deal with their selves (17.7\%), and finally do not know how to report (20\%).

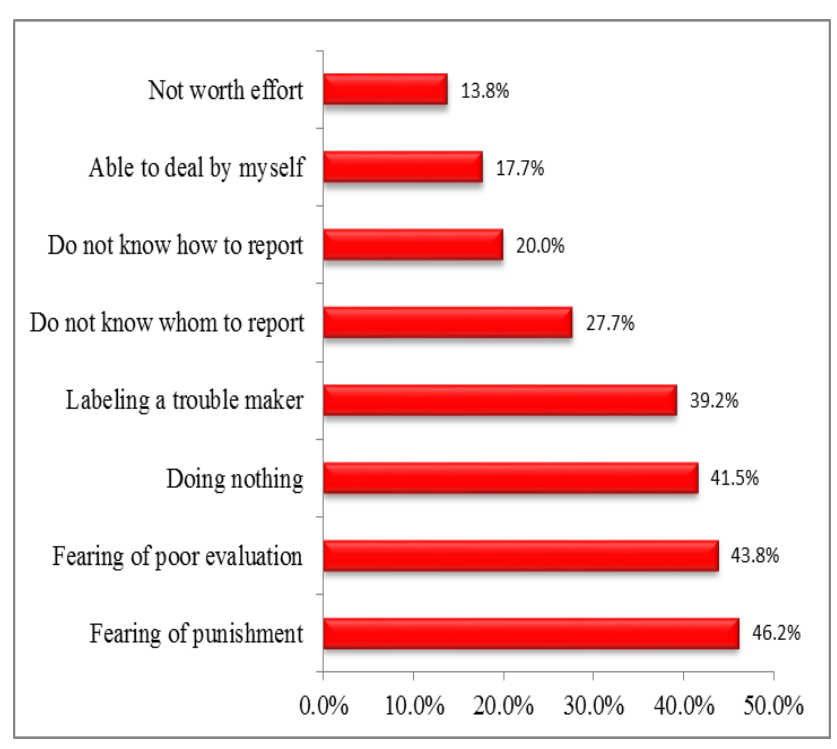

Figure 6. Frequency of reasons for not reporting about bullying behaviors among Saudi female nursing students

Table 4. Relation between types of bullying behaviors and female nursing students' academic year

\begin{tabular}{|c|c|c|c|c|c|c|}
\hline $\begin{array}{c}\text { Types of } \\
\text { bullying } \\
\text { behaviors }\end{array}$ & $\begin{array}{c}\text { Academic } \\
\text { year }\end{array}$ & $\mathbf{N}$ & Mean & SD & $\mathbf{F}$ & $P$ value \\
\hline \multirow{4}{*}{$\begin{array}{c}\text { Verbal } \\
\text { bullying } \\
\text { behavior }\end{array}$} & Sophomore & 19 & 47.5 & 7.67 & \multirow{4}{*}{4.1945} & \multirow{4}{*}{$0.007 * *$} \\
\hline & Junior & 30 & 48.1 & 24.46 & & \\
\hline & Senior & 60 & 47.73 & 22.88 & & \\
\hline & Interns & 21 & 61.77 & 17.28 & & \\
\hline \multirow{4}{*}{$\begin{array}{l}\text { Physical } \\
\text { bullying } \\
\text { behavior }\end{array}$} & Sophomore & 19 & 22.37 & 17.02 & \multirow{4}{*}{3.1482} & \multirow{4}{*}{$0.027 *$} \\
\hline & Junior & 30 & 27.50 & 22.98 & & \\
\hline & Senior & 60 & 33.89 & 9.89 & & \\
\hline & Interns & 21 & 39.30 & 23.21 & & \\
\hline \multirow{4}{*}{$\begin{array}{c}\text { Psychological } \\
\text { bullying } \\
\text { behavior }\end{array}$} & Sophomore & 19 & 38.83 & 8.14 & \multirow{4}{*}{2.8850} & \multirow{4}{*}{$0.038^{*}$} \\
\hline & Junior & 30 & 40.39 & 25.17 & & \\
\hline & Senior & 60 & 42.17 & 22.55 & & \\
\hline & Interns & 21 & 54.88 & 22.17 & & \\
\hline
\end{tabular}

$\mathrm{P}<0.01$ Highly Significant $\& \mathrm{P}<0.05$ Significant.

Table 4 states the relation between types of bullying behaviors and female nursing students' academic year. There were statistical significant differences between different types of bullying behaviors and nurse students' academic year. The students of internship year had the highest mean values (61.77, 54.88 \& 39.30) for verbal, psychological and physical forms of bullying behaviors respectively. While, the students of sophomore year had the lowest mean values (47.5, 38.83 \& 22.37) for verbal, psychological and physical types of bullying behaviors respectively.

Table 5 states the relation between consequences of bullying behaviors and female nursing students' academic year. It was apparent from the previous table; the nurses' interns (56.70) were experienced psychological symptoms. 
While the students of sophomore and senior years were more exposed to physiological symptoms (52.07), and behavioral symptoms (41.77) respectively. There were statistical significance differences between the participants' academic years and different consequences of bullying behaviors.

Table 5. Relation between consequences of bullying behaviors and female nursing students' academic year

\begin{tabular}{|c|c|c|c|c|c|c|}
\hline \begin{tabular}{|c|}
$\begin{array}{c}\text { Consequences } \\
\text { of bullying } \\
\text { behaviors }\end{array}$ \\
\end{tabular} & $\begin{array}{c}\text { Academic } \\
\text { year }\end{array}$ & $\mathbf{N}$ & Mean & SD & $\mathbf{F}$ & P value \\
\hline \multirow{4}{*}{$\begin{array}{c}\text { Physiological } \\
\text { Symptoms } \\
\text { scale }\end{array}$} & Sophomore & 19 & 52.07 & 22.72 & \multirow{4}{*}{6.50189} & \multirow{4}{*}{$0.0004^{* * *}$} \\
\hline & Junior & 30 & 31.67 & 8.16 & & \\
\hline & Senior & 60 & 51.96 & 25.09 & & \\
\hline & Interns & 21 & 48.30 & 22.41 & & \\
\hline \multirow{4}{*}{$\begin{array}{l}\text { Psychological } \\
\text { Symptoms } \\
\text { scale }\end{array}$} & Second & 19 & 58.22 & 27.70 & \multirow{4}{*}{2.582829} & \multirow{4}{*}{0.0563} \\
\hline & Third & 30 & 41.77 & 13.72 & & \\
\hline & Fourth & 60 & 55.31 & 29.40 & & \\
\hline & Interns & 21 & 56.70 & 21.79 & & \\
\hline \multirow{4}{*}{$\begin{array}{c}\text { Behavioral } \\
\text { Symptoms } \\
\text { scale }\end{array}$} & Sophomore & 19 & 34.54 & 24.15 & \multirow{4}{*}{6.885038} & \multirow{4}{*}{$0.0002^{* * *}$} \\
\hline & Junior & 30 & 18.96 & 11.89 & & \\
\hline & Senior & 60 & 41.77 & 27.65 & & \\
\hline & Interns & 21 & 28.57 & 19.02 & & \\
\hline
\end{tabular}

\section{Discussion}

Historically, bullying from academicians has been an untouched area of research until now, due to the assumption that faculty members should follow high standards of ethics and professionalism [1]. Unfortunately, when the students feel bullied by faculty members /clinical instructors who abuse of power, the students will not only mistrust and disrespect for those faculty members, but also they may experience collateral damage in their learning and become perpetrators of bullying behaviors with others. The problem of bullying is far-reaching, therefore, this study emphasizes to study the phenomena of bullying and coping strategies among Saudi female students during their nursing education.

In this study, the majority (83.8\%) of respondents $(\mathrm{N}=130)$ experienced bullying behaviors during the period of studying in nursing education program. Most of participants estimated the extent of bullying behaviors in the academic environment as a major problem, and more than half of them reported that bullying behaviors would affect their performance. These findings might be due to negative culture of unhealthy and non-supportive learning environment, which aggregate the problem. When the students exposed to bullying during the learning process, it prevent them from achieving the competent level of performance and create unsafe environment. These results are in the same line with Clarke, et al. [15] who surveyed 674 nursing students, $88.7 \%$ of them experiencing at least one act of bullying behaviors. Abd-Elrahman [22] revealed that $87.6 \%(\mathrm{~N}=709)$ of Egyptians' student nurses are experiencing bullying behaviors. Accordingly, Seibel and Fehr [3] recognized bullying behaviors as common complaints among nursing students and routine experiences in academia and clinical setting. In this aspect, Smith, et al. [24] illustrated that the extent of bullying behaviors experienced by nursing students is unclear as percentages range among studies.
The results showed that clinical practice setting is the most frequent learning environment involving bullying behaviors, followed by traditional classroom, then skills laboratories. The explanation for this finding may be due to unfamiliar environment with the clinical learning, lack of experiences, and frequent ward rotations among different courses. Similarly, Ferns and Meerabeau [16] found that nursing students in the United Kingdom (UK) were vulnerable to bullying during clinical rotations due to intensive clinical contact time, the short duration of clinical rotations, and inexperience. In another study conducted in United States (US), Smith, et al. [24] confirmed that nursing students experience various forms of bullying behaviors in clinical setting. In contrast, recent research of Seibel and Fehr [3] emphasized that different types of bullying can be happened in class or clinical settings within and between student and faculty groups.

In this study, the most likely source to be bully among Saudi female nurse students was classmate (58.5\%), followed by faculty members (53.1\%), then clinical instructors (50\%) and after that patients or patients' family $(47.7 \%)$. In the same scene, the least three frequent perpetrators of bullying behaviors were nursing staff (38.5\%), administrative staff (33.8\%), and finally physician (17.7\%). Similarly, in Cerit, et al. [2] study, which developed an instrument of bullying behaviors in nursing education, stated that the nursing students exposed to bullying behaviors by classmates, instructors, clinical nurses, patient's relatives, and doctors. Moreover, these findings supported by Celik and Bayraktar [25] study, who found that the main perpetrators of academic abuse among Turkey nursing students was classmates.

On contradictory, an Australian study conducted by Hopkins, et al. [15] identified that the dominant perpetrator of nursing students during clinical practice was the patient followed by registered nurses and colleagues. While in another study of Kassem, et al. [17] issued that the major perpetrator of bullying behaviors comes from the staff nurse, while the faculty and classmate were the lowest sources of bullying behaviors.

Based on the current findings, verbal abuse was the most frequent bullying behaviors form that reported by Saudi female nursing students, followed by psychological and physical abuse. These results confirmed by Celik and Bayraktar [25] who found that verbal abuse was the most frequently reported type of bullying. Concerning verbal bullying behaviors, the students reported that they always threaten with poor evaluation (45.4\%\%) and use belittle behavior for their efforts (36.9\%), as well as they often experience failing to acknowledge significant clinical or academic achievement (40\%), use offensive language or inappropriate non-verbal signs in front of others (31.5\%), and persistent criticism of work/effort (27.7\%). In the same line, Cooper, et al. [26] surveyed nursing students ( $\mathrm{N}=636$ ) who reported that they got a bad marks as a punishment (88.2\%), lacked acknowledgement when making any significant accomplishments (80\%), and overloaded with work (84\%).

Natarajan, et al. [27] documented that nurse students confronted bullying in the form of harassing comments (21.3\%), general taunts (30.1\%), and threating of physical harm (34.2\%). Furthermore, Abd-Elrahman [22] stated that undervaluing of efforts (83.2\%) and negative remarks 
about becoming a nurse (81.9\%) in clinical setting were experienced by nursing students. Celik and Bayraktar [25] studied the state of abuse in nursing education in Turkey, and found that students being punished with poor grades, yelled or shouted, and may victims by rumors spread about them.

Pertaining physical bullying behaviors, results also demonstrated that nurse students always experience excessive monitoring of work (30\%), as well as often continuously assign tasks over their capacity (34.6\%) and be physically isolated (33.8\%). Nevertheless, they rarely experience changing duties without being told (58.5\%), and never experience actual threating physically (58.5\%) and removing areas of responsibility without warning (53.8\%). In Egypt study, Abd-Elrahman [22] found physical abuse is the least reported bullying behaviors among nursing students. On the contrary, in the Australian study identified physical violence in the workplace experienced by nursing students as the most frequent form of bulling in clinical setting [14].

As regard psychological behaviors, it should be noted that the respondents always experience repeating reminders of mistakes (31.5\%) and limit self-expression (26.9\%). Additionally, they often experience attempting to demoralize (33.8\%), use undue pressure to produce order (31.5\%), and insist to give them negative criticism (24.6\%). However, they never treated with hostility (40.8\%) and denial the learning opportunities (27.7\%). Abd-Elrahman [22] stated that nursing students treated with hostility (61.7\%); ignored (60.4\%); and resentment towards them (53.3\%). On the contrary, Smith, et al. [24] reported that being denied an opportunity to learn experienced by nursing students through not giving them opportunities to perform patient care, and feeling of impatient with them or not explaining what was going on with the patient.

The current study results documents that psychological symptoms are the most frequently reported bullying behaviors' consequences among nursing students, followed by physiological symptoms and then behavioral symptoms. In psychological symptoms, the students always get angry/anxious (32.3\%), dissatisfied (30\%), think to leave profession (26.2\%) \& be fearfulness (23.8\%). They often feel depressed or sad (25.4\%), and sometimes increase absenteeism (26.9\%). On the other hand, the most frequent physiological symptoms include the female student always feel insomnia (34.6\%), extreme fatigue (33.1\%), losing weight (32.3\%) and losing of appetite (26.9\%). While, the students become fast irritable (23.8\%) and withdrawal (33.8\%) as behavioral symptoms.

Longo, [28] in his study mentioned that the psychological consequences of bullying among nursing students include panic attacks, fear, anxiety, depression, drug use, and social isolation. While the physiological symptoms include headaches, sleep disorders, high blood pressure, anorexia, gastrointestinal problems, and suicide attempts.

In other words, Smith, et al. [24] described the psychological symptoms of bullying behaviors among nursing students involve dread, disbelief, worry, feeling self-conscious, loss of confidence, and decreased self-esteem. In the same study, the physical symptoms manifested by crying or feeling physically sick. While the emotional symptoms incorporated feeling scared, nervous, irritated, angry, pissed off and uncomfortable during and after bullying events. Abd-Elrahman [22] reported that the effect of bullying felt among nursing students was getting angry (88.6 \%), forgetful (68 \%), and loss of concentration (58.9\%). Accordingly, the effect of direct negative behaviors can be ranged from practical jokes and mild violence to physical violence [2].

It is clear from the study's findings that the most reported coping strategies of bullying behaviors experienced by Saudi female nursing students were putting up barriers (39.2\%), pretending not to observe the behavior (38.5\%), doing nothing (36.9\%), demonstrating similar behavior (29.2\%) and replying directly to the bully (25.4\%). These findings may be explained by the fact that nursing students saw themselves as powerless individuals due to their learning role and they considered bullying as natural culture in academic setting.

In a somewhat similar study conducted by Cooper, et al. [26] documented that the passive responses to the bullying behaviors were did nothing, put up barriers and pretended not to see the behavior, while the active responses were spoken directly to the bully and reported the behavior to a superior/authority. In a comparative Egyptian study of Kassem, et al. [17] denoted that the highest coping strategies used in both groups of nurses students (faculty and technical health institute) were pretending not to see the behavior and reporting the behavior to a superior / authority. While, demonstrating similar behavior is the lowest coping strategy used by both groups.

Conversely, the study of Karatas, et al. [10] who surveyed 202 nursing students in different academic years addressed that the large percentage of them used face-toface communication with the perpetrators of bullying, reporting the incident to higher authorities, and working in a planned manner to avoid criticism. The previous study justified these findings due to both social and occupational culture, which considered as crucial determinants of student attitudes.

According to the current study results, the most frequently reasons of not reporting bullying behaviors experienced by participants were fearing of punishment $(46.2 \%)$, fearing of poor evaluation (43.8\%), belief if it is known doing nothing (41.5\%), labeling a trouble maker (39.2\%), and do not know whom to report (27.7\%). In a study of Abd-Elrahman, [22], the most commonly reported reasons why students did not report bullying were fear of poor evaluation (65.6\%) and not worth the effort (56.4\%).

It was apparent from the study findings; there were statistical significant differences between different types of bullying behaviors and nurse students' academic year. The nurse interns were the dominants participants having the highest mean values for different forms of bullying behaviors. While, the students of sophomore year had the lowest mean values for different forms of bullying behaviors. The reason for this finding may be due to the nurse interns have passed with many situations of bullying behaviors during the years of studying in academic setting, as well as in clinical setting. While, the students of sophomore year have not enough experiences and little period of training in clinical rotations. However, both of 
them experience all forms of bullying regardless their years of experiences in nursing education program. Clarke, et al. [15] study supported this finding and highlighted that the bullying behaviors did not differ significantly by year of study, but the students of fourth-year tended to report the highest percent of bullying, followed by third, second, and first.

The findings also clarified statistical significance differences between the participants' academic years and different consequences of bullying behaviors. The nurses' interns were more exposed to psychological symptoms of bullying behaviors (56.70). While the students of sophomore and senior years were more exposed to physiological symptoms (52.07), and behavioral symptoms (41.77) respectively. While, Abd-Elrahman, [22] emphasized that there were no significant differences between nurse students at the different academic years (first, second, third \& fourth) and the bullying effects.

\section{Recommendations}

Based on the study findings, there is a need to establish policy for identifying the legal implications in behaving with bullying behaviors not only towards the nurses' students but also towards the faculty. Both of them should be aware with a reliable procedure that must be follow for reporting the bullying incident in a respectful and nonthreatening environment with confidentiality responding. Increasing the students and faculty awareness towards the appropriate coping strategies for dealing with the cycle of bullying process through conducting workshops and seminars. The academic nursing administrators must integrate the bullying issue in the curriculum of nursing education program for knowing how to manage, cope and interact professionally in these situations. Developing a rapport relationship between the nurse students and faculty members especially the clinical instructors. Moreover, there is a need for conducting further longitudinal study to identify the root causes and indirect effects of bullying behaviors in nursing academic and clinical settings environment.

\section{Conclusion}

In conclusion, there is an evidence for presence of bullying phenomena among female nursing students that deserve to be studied especially in Saudi Arabia. Furthermore, results of the current study confirmed that Saudi female nursing students experienced different forms of bullying behaviors in the clinical and traditional classroom settings. The main perpetrators reported by them were classmate, faculty member, clinical instructor and patients or patients' family. The consequences of bullying behaviors were mainly psychological, physiological and behavioral symptoms. Putting up barriers, pretending not to observe the behavior, doing nothing, and demonstrating similar behavior and replying directly to the bully were the most common coping strategies used by nurse students. The most frequently reasons of not reporting bullying behaviors experienced by participants were fearing of punishment and poor evaluation, doing nothing, labeling a trouble maker, and do not knowing whom to report.

\section{References}

[1] Misawa, M., Cuts and bruises caused by arrows, sticks, and stones in academia: Theorizing three types of racist and homophobic bullying in adult and higher education. Adult Learning, 2015. 26(1): p. 6-13.

[2] Cerit, K., Keskin, S.T., and Ekici, D., Development of Instrument of Bullying Behaviors in Nursing Education based on Structured Equation Modeling. Asian Nursing Research, 2018. 12: p. 245-250.

[3] Seibel, L.M. and Fehr, F.C., They can crush you": Nursing students' experiences of bullying and the role of faculty. Journal of Nursing Education and Practice, 2018. 8(6).

[4] Sittichai, R. and Smith, P.K., Bullying and Cyberbullying in Thailand: A Review International Journal of Cyber Society and Education, 2013. 6(1): p. 31-44.

[5] Hoel, H., Gigay, S.I., and Davidsonz, M.J., Expectations and realities of student nurses' experiences of negative behaviour and bullying in clinical placement and the influence of socialization processes. Health Services Management Research, 2016. 20: p. 270-278.

[6] Milesky, J.L., et al., Promoting a culture of civility in nursing education and practice. Journal of Nursing Education and Practice, 2015. 5(8): p. 90-94.

[7] American Nursing Association, Professional Issues Panel on Incivility, Bullying, and Workplace Violence, in New Position Statement, Board of Directors, Editor. 2015. Available at: file://C:/Users/ITU/Downloads/PosStat-Endorsed-ANAIncivility-Bullying-Violence.pdf.

[8] Janet, W., An exploration of bullying behaviours in nursing: a review of the literature. British Journal of Nursing, 2016. 25(6): p. 303-306.

[9] Wilkins, J., The use of cognitive reappraisal and humour as coping strategies for bullied nurses. International Journal of Nursing Practice, 2014. 20: p. 283-92.

[10] Karatas, H., Ozturk, C., and Bektas, M., A Study of Bullying Against Nursing Students. The Journal of Nursing Research, 2016. 00(0): p. 1-5.

[11] Ball, J. and Pike, G., Bullying, harassment and assault: preliminary findings from the RCN Working Well, 2000 Survey. Royal College of Nursing, London. 2001.

[12] Hutchinson, M., Bullying as workgroup manipulation: A model for understanding patterns of victimization and contagion within the workgroup. J Nurs Management, 2013. 21(3): p. 563-71.

[13] Faucher, C., Jackson, M., and Cassidy, W., When online exchanges byte: An examination of the policy environment governing cyberbullying at the university level. Canadian Journal of Higher Education, 2015. 45(1): p. 102-21.

[14] Hopkins, M., Fetherston, C.M., and Morrison, P., Prevalence and characteristics of aggression and violence experienced by Western Australian nursing students during clinical practice. Contemporary Nurse, 2014. 49: p. 113-21.

[15] Clarke, C.M., et al., Bullying in Undergraduate Clinical Nursing Education. Journal of Nursing Education, 2012. 51(5): p. 269-276.

[16] Ferns, T. and L. Meerabeau, Verbal abuse experienced by nursing students. Journal compilation, Blackwell Publishing Ltd, 2008. 61: p. 436-44.

[17] Kassem, A.H., Elsayed, R.S., and Elsayed, W.A., Bullying Behaviors and Self Efficacy among Nursing Students at Clinical Settings: Comparative Study. Journal of Education and Practice, 2015. 6(35): p. 25-36.

[18] Foster, B., Mackie, B., and Barnett, N., Bullying in the health sector: A study of bullying of nursing students. New Zealand Journal of Employment Relations, 2004. 29(2): p. 67-83.

[19] Zinan, N., Bully Victim Identification and Intervention Program for School Nurses. 2010, University of Massachusetts Amherst.

[20] Birksa, M., et al., A 'rite of passage?' Bullying experiences of nursing students in Australia. Collegian 25 (2018) 45-50, 2018. 25: p. 45-50. 
[21] Manzoor, Z., et al., Professional Stressors and Coping Strategies among Nurses. Journal of Health, Medicine and Nursing, 2018. 52: p. 43-47.

[22] Abd-Elrahman, R.M., Perception of Student Nurses' Bullying Behaviors and Coping Strategies Used in Clinical Settings, in Nursing Education Research Conference. Sigma Theta Tau International, National League of Nursing, Editor. 2014: Indianapolis, Indiana, USA.

[23] Cook, C., et al., Variability in the prevalence of bullying and victimization: A cross-national and methodological analysis. Handbook of bullying in schools: An international perspective. New York: Routledge/Taylor \& Francis Group, 2010.
[24] Smith, C.R., et al., Seeing Students Squirm: Nursing Students' Experiences of Bullying Behaviors During Clinical Rotations. J Nurs Educ., 2016. 55(9): p. 505-513.

[25] Celik, S.S. and Bayraktar, N. A study of nursing student abuse in Turkey. Journal of Nursing Education. 2004. 43(7): 330-336.

[26] Cooper, J.R.M., et al., Students' perceptions of bullying behaviors by nursing faculty. Issues in Educational Research, 2011. 21(1).

[27] Natarajan, J., Muliira, J.K., and Colff J.V. Incidence and perception of nursing students' academic incivility in Oman. BMC Nursing, 2017. 16(19): p. 1-9.

[28] Longo, J., Horizontal violence among nursing students. Archives of Psychiatric Nursing, 2007. 21(3). 